\title{
Decreased nailfold capillary density in Raynaud's phenomenon: a reflection of immunologically mediated local and systemic vascular disease?
}

\author{
P M HOUTMAN, C G M KAllenberg, A A WOUdA, AND T H THE \\ From the Department of Internal Medicine, University Hospital, Groningen, the Netherlands
}

SUMMARY Nailfold capillary patterns were studied in 107 patients with Raynaud's phenomenon (RP), including patients with $(n=39)$ and without $(n=68)$ connective tissue disease (CTD). Capillary density was decreased in patients with sclerodactyly, digital ulcers, tuft resorption, and telangiectasia, compared with patients without these symptoms. In addition, an inverse relationship was found between the severity of RP at first presentation (as graded by photoelectric plethysmography during cooling) and the capillary density in patients with CTD $(\mathrm{r}=-0.45 ; \mathrm{p}<0.05)$. In the total group of patients nailfold capillary density was inversely related to organ system involvement $(\mathrm{r}=-0.52 ; \mathrm{p}<0 \cdot 01)$. Decreased nailfold capillary density was observed, in particular, in patients with oesophageal hypomotility and in patients with chest $x$-rays compatible with interstitial fibrosis. As to factors supposedly involved in the pathogenesis of vascular changes in CTD, the presence of autoantibodies, increased levels of circulating immune complexes, and increased levels of acute phase reactants were all associated with a decreased number of nailfold capillaries. We conclude that loss of nailfold capillaries as observed by microscopy is a reflection of local and systemic vascular disease.

Key words: capillary microscopy, scleroderma, CREST, MCTD.

Raynaud's phenomenon (RP) may present as an idiopathic or primary phenomenon, or as part of a connective tissue disease (CTD) (so-called secondary RP). It may precede the development of these diseases by many years. ${ }^{1-3}$ There is some evidence that both Raynaud's phenomenon and other manifestations of CTD have a common, possibly immunologically mediated, vascular basis. Indeed, in scleroderma functional and histological studies have shown that vascular abnormalities predominantly affecting the small blood vessels not only appear in the fingers ${ }^{5}$ but also in internal organs, such as lung, kidney, and heart. ${ }^{6-9}$ Interestingly, capillary abnormalities appear in the nailfold of patients with connective tissue diseases at an early stage and can be visualised easily by microscopy. ${ }^{10}$ By this method it is possible to describe nailfold capillary density

Accepted for publication 11 March 1985.

Correspondence to Dr C G M Kallenberg, Dept of Internal Medicine, University Hospital, Oostersingel 59, 9713 EZ Groningen, the Netherlands. and morphological changes, such as enlargements of capillary loops, in a reproducible way. ${ }^{17}$ In a previous study we have shown that the nailfolds of patients with secondary RP, i.e., scleroderma, CREST (calcinosis, Raynaud's phenomenon, oesophagitis, sclerodactyly, telangiectasia) syndrome, or mixed connective tissue disease (MCTD), are characterised by a decreased number of capillaries and an increased number of enlarged loops when compared with those of either patients with primary RP or healthy controls. ${ }^{17}$ In the present study we evaluate whether nailfold capillary abnormalities in patients presenting with RP are indicative of a more generalised vascular disease. From this point of view we investigated nailfold capillary findings in relation to symptoms of local vascular disease and in relation to organ system involvement. In addition, immunological and inflammatory factors, supposed to have pathophysiological significance with respect to vascular changes in CTD, were studied in relation to capillary findings in the nailfold. 


\section{Patients and methods}

\section{PATIENTS}

One hundred and seven patients with Raynaud's phenomenon (RP) were evaluated, including 39 patients with CTD and 68 patients without CTD. Diagnosis of CTD, i.e., scleroderma, ${ }^{11}$ CREST, ${ }^{12}$ and $\mathrm{MCTD},{ }^{13}$ was made according to previously described criteria.

Data of the patients are given in Table 1. At the time of the investigation none of the patients was being treated with immunosuppressive agents; two patients with scleroderma and three patients with MCTD were being treated with low doses of corticosteroids. The severity of RP had been graded from 0 to 5 by photoelectric plethysmography, both for cooling and warming ${ }^{14}$ at the first presentation of the patient at the outpatient clinic. In nine patients plethysmography during cooling could not be performed because of severe impairment of finger blood flow already at room temperature. A detailed medical history was taken, and physical examination was performed on all patients by one physician according to a protocol. The protocol was particularly directed at the presence of sclerodactyly, non-artificial ulcers or pitting of the fingers, proximal scleroderma as defined by Masi et al., ${ }^{11}$ arthralgia or arthritis, or both, and the presence of telangiectasia on the hands. In addition, the following studies were made: roentgenograms of the hands and chest, and a barium swallow study in the horizontal position. Additional studies were made when indicated. Roentgenograms of the hands were evaluated by a radiologist, and the chest $x$-ray by a chest physician not informed about the clinical data. Criteria for organ system involvement (according to Kallenberg, ${ }^{12}$ with some modifications) are given in Table 2.

\section{LA B ORATORY STUDIES}

Comprehensive laboratory studies were performed on all patients. These included: complete blood count; Westergren erythrocyte sedimentation rate (ESR); urinalysis; serum levels of urea, creatinine, and creatine phosphokinase, all according to stan- dard techniques; levels of immunoglobulins an $\$$ C-reactive protein (CRP) as determined by nephelometry; rheumatoid factor by the latex fixation tes (considered positive at a dilution of $1: 80$ ) and by sheep cell agglutination methods (positive at dilution of 1:16); immunofluorescent antinuclea antibody (ANA) with fibroblast monolayers as substrate (positive at a dilution of 1:40); an circulating immune complexes (CIC).

For the determination of CIC freshly drawn ser $\vec{D}$ were kept frozen at $-80^{\circ} \mathrm{C}$. Three assays were used $\vec{i}$ polyethyleneglycol precipitation (PEG) and soligh phase C1q-binding enzyme-linked immunosorben assay (C1q-ELISA) as described previously, ${ }^{15}$ anc the indirect granulocyte phagocytosis test (IGPT) as described by Van Wingerden with some slighe modifications. ${ }^{16}$

NAILFOLD CAPILLARY MICROSCOPY Nailfold capillary microscopy was performed a $\vec{s}$ described in a previous report. ${ }^{17} \mathrm{~A}$ standard pro $\Phi$ tocol was used for qualitative and quantitatived evaluation of nailfold capillary patterns. Briefly, the nailfolds were examined by widefield microscopy with an Olympus stereozoom microscope. Pattegns were described qualitatively, especially with respeceo to the presence of exudates, giant loops, busidy patterns, and coiled balls. Next the nailfolds werfe photographed with an Agfa-ortho $25 \mathrm{film}$. Thes photomicrographs of the fourth fingers were evalu용 ated by two independent observers not informec about the patients. The quantitative items, i.e., totaP

Table 2 Criteria for organ system involvement

\section{Skin Hidebound skin proximal to the fingers}

2. Oesophagus Loss of peristalsis in barium swallow studies in

3. Lungs horizontal position

Bibasilar pulmonary markings on chest roentgenogram

4. Joints

Arthralgia or arthritis, or both at the time of investigation

5. Muscles Creatine phosphokinase $>150$ IU (normal value $<50 \mathrm{IU}$ ) and/or electromyogram consistent with myositis and/or muscle biopsy consistent with myositis

Table 1 Diagnosis, sex, age, and duration of RP of 107 patients with Raynaud's phenomenon

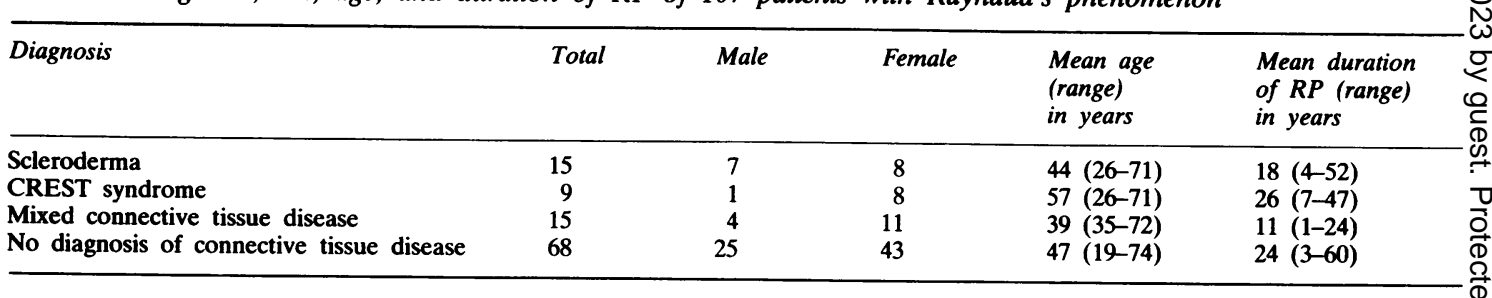




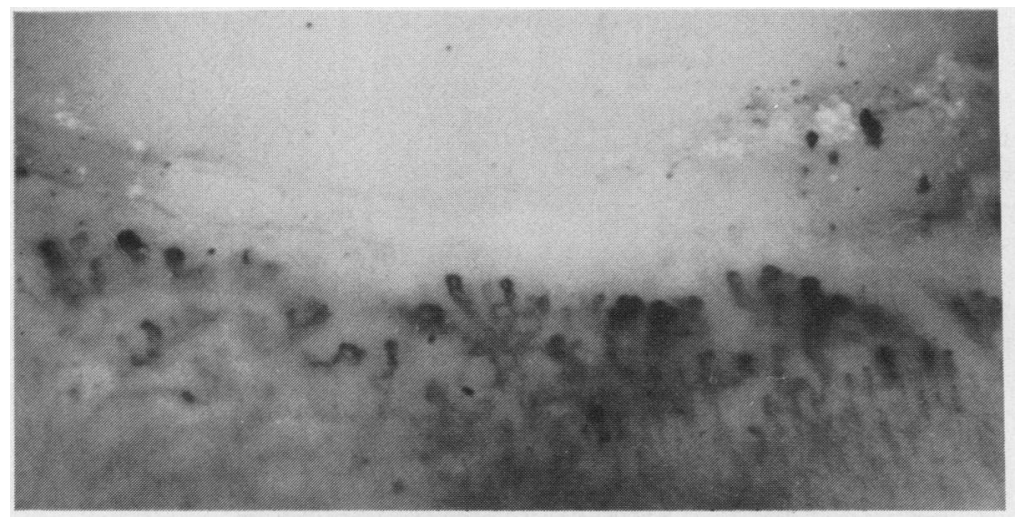

Fig. 1 Photomicrograph of the nailfold of a patient with MCTD showing low capillary density and enlargement of loops. $(\times 13)$.

number of capillaries and number of enlarged loops, were scored in a defined area of $5 \mathrm{~mm}$ in the distal row of capillaries. The meah of the scores of both observers was determined. The mean of the scores of both fourth fingers per patient was used in statistical processing for reasons described previously. ${ }^{1}$ A representative photomicrograph of the nailfold of a patient with MCTD showing a low capillary density and enlarged loops is given in Fig. 1.

\section{STATISTICAL ANALYSIS}

Groups of patients with and without morphological changes of the fingers and groups of patients with and without organ system involvement were evaluated for differences in nailfold capillary patterns. The Mann-Whitney test was used to analyse intergroup variations. Spearman's rank correlation tests were used to evaluate the relationship between nailfold capillary density and severity of RP or organ system involvement. p Values less than 0.05 were considered significant. Only quantitative parameters of nailfold capillary microscopy (total number of loops and number of enlarged loops) were used in this study, since the occurrence of qualitative parameters such as bushy patterns and giant loops was too low for statistical analysis (by $\chi^{2}$ test) of intergroup variations.

\section{Results}

NAILFOLD CAPILLARY FINDINGS AND MORPHOLOGICAL CHANGES OF

THE FINGERS

One hundred and seven patients with RP were evaluated according to the protocol. The clinical data of these patients are summarised in Table 3. To assess the relationship between nailfold capillary findings and morphological changes in the fingers in patients with RP we compared capillary density and the number of enlarged loops in patients with and without morphological changes. The number of capillary loops in the nailfold was decreased in patients with sclerodactyly $(\mathrm{p}<0 \cdot 01)$, non-artificial ulcers or pitting of the fingers $(p<0.01)$, tuft resorption $(p<0.01)$, and telangiectasia on the

Table 3 Clinical data of 107 patients with Raynaud's phenomenon

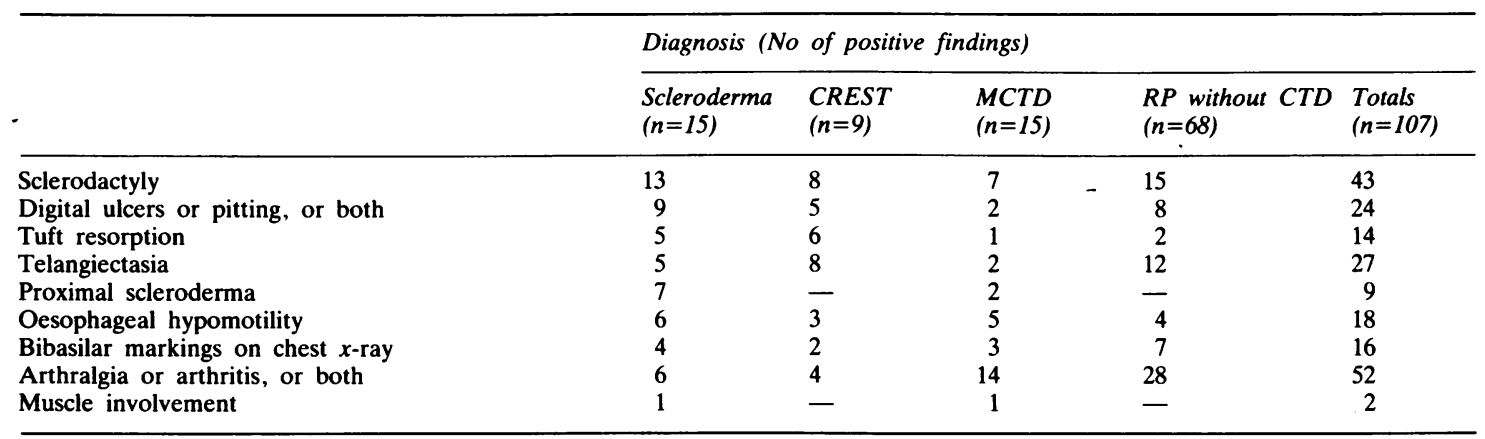


hands $(p<0.01)$, all compared with groups of patients without these symptoms (Table 4). When patients with CTD were considered separately the same findings were observed with respect to tuft resorption and telangiectasia. Furthermore, the number of enlarged loops was increased in patients with sclerodactyly $(\mathrm{p}<0.05)$, tuft resorption $(\mathrm{p}<0.05)$, and telangiectasia $(\mathrm{p}<0.01)$, compared with groups without these features.

NAILFOLD CAPILLARY DENSITY AND THE SEVERITY OF RP AT FIRST PRESENTATION A correlational analysis was used to determine whether nailfold capillary density was related to the severity of RP at first presentation as graded by photoelectric plethysmography. In the total group of patients with RP a significant correlation was found between nailfold capillary density and photoelectric plethysmography, both on cooling $(r=-0.34$; $\mathrm{p}<0.01)$ and on warming $(\mathrm{r}=-0.27 ; \mathrm{p}<0 \cdot 01)$. This correlation was not found when only the group of patients without CTD was studied. The relation in secondary RP between nailfold capillary density and the severity of RP (as graded during cooling) is represented in Fig. $2(r=-0.45 ; \mathrm{p}<0.05)$.

NAILFOLD CAPILLARY FINDINGS AND ORGAN SYSTEM INVOLVEMENT

Correlational analysis was performed to assess the relation between nailfold capillary density and organ system involvement. In the entire group of patients with RP capillary density in the nailfold was inversely related to the number of organs affected $(r=-0.52 ; p<0 \cdot 01)$ (Fig. 3).

Table 4 Nailfold capillary findings related to morphological changes of the fingers in 107 patients with Raynaud's phenomenon

\begin{tabular}{|c|c|c|}
\hline & $\begin{array}{l}\text { Total number of } \\
\text { capillary loops, } \\
\text { median (range) }\end{array}$ & $\begin{array}{l}\text { Number of } \\
\text { enlarged loops, } \\
\text { median (range) }\end{array}$ \\
\hline \multicolumn{3}{|l|}{ Sclerodactyly } \\
\hline present $(n=53)$ & $37 \quad(7-50) \ddagger$ & $2(0-9) \dagger$ \\
\hline absent $(n=54)$ & $41(15-50)$ & $1(0-16)$ \\
\hline \multicolumn{3}{|l|}{ Ulcers/pitting } \\
\hline present $(n=24)$ & $34 \quad(7-47) \ddagger$ & $2(0-10)$ \\
\hline absent $(n=83)$ & $40(11-50)$ & $1(0-16)$ \\
\hline \multicolumn{3}{|l|}{ Tuft resorption } \\
\hline present $(n=14)$ & $22 \quad(7-39) \ddagger$ & $3(0-9) \dagger$ \\
\hline absent $(n=93)$ & $42(15-50)$ & $1(0-16)$ \\
\hline \multicolumn{3}{|l|}{ Telangiectasia } \\
\hline present $(n=27)$ & $30 \quad(7-50) \ddagger$ & $3(0-10) \ddagger$ \\
\hline absent $(n=80)$ & $41(15-50)$ & $1(0-17)$ \\
\hline
\end{tabular}

${ }^{*}$ In a $5 \mathrm{~mm}$ area of the distal row in the nailfold. $\dagger \mathrm{p}<0.05 ; \ddagger \mathrm{p}<0.01$. number of

capillaries

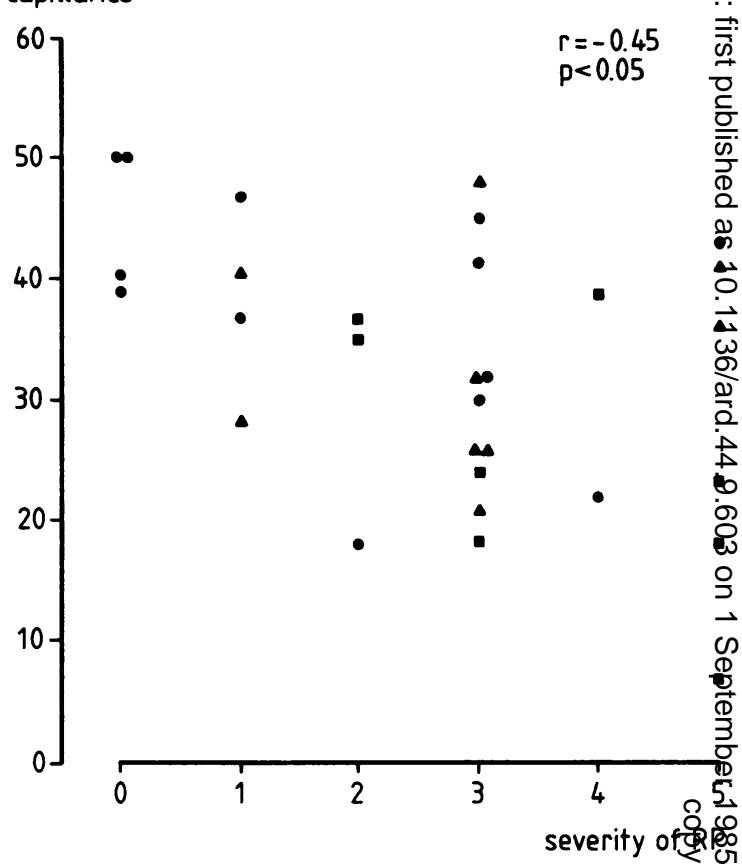

Fig. 2 Nailfold capillary density related to the severity oके. $R P$ as graded by photoelectric plethysmography during cêtd provocation in patients with secondary $R P$. O scleroderma; $\square$ CREST; $\triangle$ MCTD.

Considering each organ system separately the capillary density in the nailfold was decreased ing patients with hypomotility of the oesophagus $(\mathrm{p}<0.01)$ and lung involvement as defined byọ bibasilar markings on $x$-ray $(p<0 \cdot 01)$. Capillary density was not decreased in patients with proxima $\bar{L}$ scleroderma compared with patients without this' symptom. The number of enlarged loops was increased in patients with lung involvemento $(\mathrm{p}<0.05)$ and patients with arthralgia $(\mathrm{p}<0.01)^{2}$ compared with patients without lung and joinf involvement, respectively. These results are summa- $\rightarrow$ rised in Table 5. When patients with CTD were considered separately capillary density was de-ñ creased in patients with oesophageal hypomotility $(\mathrm{p}<0.01)$ but not in patients with abnormal chesto $x$-rays.

NAILFOLD CAPILLARY FINDINGS, A UTOANTIBODIES, CIC, AND ACUTE PHASE REACTANTS

Next we evaluated the possibility that humoraio factors supposed to be involved in the pathophysi-웅 ology of disease manifestations in CTD were related 
number of

capillaries

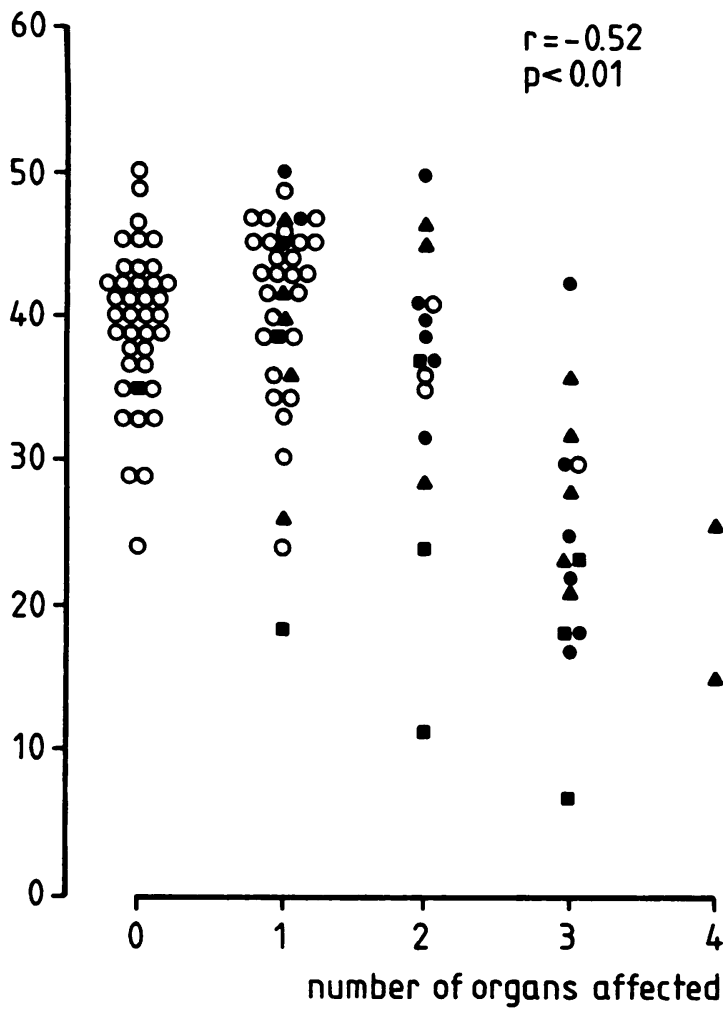

Fig. 3 Nailfold capillary density related to the number of affected organs in patients with secondary $R P$.

scleroderma; CREST; $\triangle M C T D ; O R P$ without CTD.

to nailfold capillary findings. Patients with a positive Rose-Waaler test displayed a decreased capillary density and an increased number of enlarged loops on nailfold microscopy compared with patients with a negative result with this test (Table 6). The same findings were observed for patients with a positive latex agglutination test, a positive test for antinuclear antibodies, and a positive test for circulating immune complexes as measured by indirect granulocyte phagocytosis (IGPT) (Table 6). These differences in capillary scores were not found when patients with and without immune complexes as measured by PEG assay or C1q-ELISA were compared. Acute phase reactants as parameters of inflammation (CRP, fibrinogen, ESR) were also considered in relation to nailfold capillary findings. The group of patients with an increased fibrinogen level ( $\geqslant 3 \mathrm{mg} \%$ ) had decreased capillary density compared with patients with a level of fibrinogen below $3 \mathrm{mg} \%(\mathrm{p}<0.05)$. Increased levels of CRP were associated with the presence of enlarged loops. Patients with increased ESR had a lower capillary density $(p<0.01)$ and a higher number of enlarged loops $(p<0.01)$ than patients with a normal ESR. These findings are presented in Table 6.

Table 5 Nailfold capillary findings related to organ system involvement (skin, oesophagus, lung, and joints) in 107 patients with Raynaud's phenomenon

\begin{tabular}{|c|c|c|}
\hline & $\begin{array}{l}\text { Total number of } \\
\text { capillary loops, } \\
\text { median (range) }\end{array}$ & $\begin{array}{l}\text { Number of } \\
\text { enlarged loops, * } \\
\text { median (range) }\end{array}$ \\
\hline $\begin{array}{l}\text { Proximal scleroderma } \\
\text { present }(n=9) \\
\text { absent }(n=98)\end{array}$ & $\begin{array}{lr}40 & (17-50) \\
39 & (7-50)\end{array}$ & $\begin{array}{l}2(0-3) \\
1(0-16)\end{array}$ \\
\hline $\begin{array}{l}\text { Oesophageal hypomotility } \\
\text { present }(n=18) \\
\text { absent }(n=89)\end{array}$ & $\begin{array}{l}28(11-46) \ddagger \\
40(7-50)\end{array}$ & $\begin{array}{l}3(0-10) \ddagger \\
1(0-16)\end{array}$ \\
\hline $\begin{array}{l}\text { Bibasilar markings on } \\
\text { chest } x \text {-rays } \\
\text { present }(n=16) \\
\text { absent }(n=91)\end{array}$ & $\begin{array}{l}29(7-36) \ddagger \\
39(11-50)\end{array}$ & $\begin{array}{l}4(2-9) \dagger \\
1(0-16)\end{array}$ \\
\hline $\begin{array}{l}\text { Arthralgia/arthritis } \\
\text { present }(n=52) \\
\text { absent }(n=55)\end{array}$ & $\begin{array}{lr}38 & (15-50) \\
39 & (7-50)\end{array}$ & $\begin{array}{l}2(0-16) \ddagger \\
1(0-9)\end{array}$ \\
\hline
\end{tabular}

*In a $5 \mathrm{~mm}$ area of the distal row in the nailfold. $\dagger \mathrm{p}<0.05 ; \ddagger \mathrm{p}<0.01$.

Table 6 Nailfold capillary findings related to immunological and inflammatory factors in 107 patients with Raynaud's phenomenon

\begin{tabular}{|c|c|c|}
\hline & $\begin{array}{l}\text { Total number of } \\
\text { capillary loops, } \\
\text { median (range) }\end{array}$ & $\begin{array}{l}\text { Number of } \\
\text { enlarged loops, } \\
\text { median (range) }\end{array}$ \\
\hline \multicolumn{3}{|l|}{ Rose-Waaler test } \\
\hline positive $(n=10)$ & $26(15-42) \ddagger$ & $3(1-9) \ddagger$ \\
\hline negative $(n=97)$ & $39(7-50)$ & $2(0-17)$ \\
\hline \multicolumn{3}{|l|}{ Latex agglutination test } \\
\hline positive $(n=17)$ & $26(11-48) \ddagger$ & $3(0-16) \dagger$ \\
\hline $\begin{array}{l}\text { negative }(n=90) \\
\text { ANA }\end{array}$ & $39(7-50)$ & $1(0-9)$ \\
\hline positive $(n=30)$ & $30 \quad(7-48) \ddagger$ & $2(0-16) \ddagger$ \\
\hline negative $(n=77)$ & $41(17-50)$ & $1(0-8)$ \\
\hline \multicolumn{3}{|l|}{ IGPT } \\
\hline positive $(n=19)$ & $30 \quad(7-45) \ddagger$ & $4(0-16) \ddagger$ \\
\hline negative $(n=88)$ & $40(11-50)$ & $1(0-8)$ \\
\hline \multicolumn{3}{|l|}{ Fibrinogen } \\
\hline$\geqslant 3 \mathrm{mg} \% \quad(n=34)$ & $32(7-50) \dagger$ & $2(0-9)$ \\
\hline$<3 \mathrm{mg} \%(\mathrm{n}=73)$ & $40(15-50)$ & $1(0-16)$ \\
\hline \multicolumn{3}{|l|}{ CRP } \\
\hline$\geqslant 10 \mathrm{mg} / \mathrm{ml}(\mathrm{g} / \mathrm{l}) \mathrm{n}=12)$ & $33(15-48)$ & $4(1-17) \dagger$ \\
\hline$<10 \mathrm{mg} / \mathrm{ml}(\mathrm{n}=95)$ & $39(7-50)$ & $2(0-10)$ \\
\hline \multicolumn{3}{|l|}{ ESR } \\
\hline$>20 \mathrm{~mm} / \mathrm{h} \quad(\mathrm{n}=18)$ & $29(11-50) \ddagger$ & $3(0-16) \ddagger$ \\
\hline$\leqslant 20 \mathrm{~mm} / \mathrm{h} \quad(\mathrm{n}=89)$ & $42(7-50)$ & $1(0-9)$ \\
\hline
\end{tabular}

*In a $5 \mathrm{~mm}$ area of the distal row in the nailfold. $\dagger p<0.05 ; \neq p<0.01$. 


\section{Discussion}

In this study we tried to relate nailfold capillary abnormalities to local and systemic vascular disease manifestations in patients presenting with RP.

Digital ulcers and tuft resorption may be mediated by prolonged ischaemia, inducing microthrombosis in small vessels and, subsequently, obliteration of these vessels. ${ }^{4}$ Patients with local changes, such as sclerodactyly, digital ulcers, and tuft resorption, had a lower capillary density than patients without these symptoms. Thus capillary density is apparently related to local vascular disease. This is also supported by the inverse relationship between nailfold capillary density and the severity of RP as recorded at first presentation in patients with secondary RP. The absence of such a relationship in patients with RP without connective tissue disease suggests a different pathophysiological mechanism in primary RP compared with secondary RP.

Nailfold capillaries are only visible at microscopy because of the presence of red blood cells within the capillaries. Thus microscopy cannot differentiate between loss of capillaries or absence of blood flow. In our patients decreased capillary density appeared to be related to structural vessel changes resulting in capillary drop out rather than resulting from a state of low flow with absence of red blood cells in the capillaries. This is also supported by the findings of Thompson et al. ${ }^{18}$ who found that nailfold capillary density as seen at microscopy was related to capillary density in histological sections of nailfold biopsy specimens. Whether the primary 'lesion' resulting in structural vessel changes lies at the level of the arterioles or the capillaries remains to be answered. However, the results of the plethysmographic studies, which measure flow changes at the arteriolar level, are in favour of a primary lesion located in the arterioles.

Histological studies in scleroderma have shown changes of arterioles in the viscera, skin, subcutaneous tissue, and muscles, consisting of intimal proliferation, medial hypertrophy, and irregular narrowing of the lumen. ${ }^{45}$ In particular, a study on skeletal muscle showed loss of small capillaries and an increased number of dilated vessels. ${ }^{19}$ As can be seen in Table 3 many patients with RP have symptoms of organ system involvement without fulfilling the criteria for CTD. Furthermore, the finding of a decreased capillary density or an increased number of enlarged loops in the nailfold is not necessarily limited to patients with RP as a part of CTD. ${ }^{17}$ Therefore we evaluated nailfold capillary density and the number of enlarged loops in a heterogeneous group of patients with RP and with and without CTD. We found that oesophageal and lung involvement, as defined by bibasilar markings on chest $x$-ray, correlated with decreased capillary? density. Our findings on individual organ involve- $\vec{\Rightarrow}$ ment and the inverse relationship between organ system involvement and capillary density support? widespread microvascular disease in patients with $\overline{\frac{O}{\omega}}$. secondary RP. The sclerodermatous nature of nail- $\frac{\widehat{\sigma}}{\sigma}$ fold capillaries in MCTD may be of prognostic value with respect to the final clinical development of scleroderma. ${ }^{20}$ Pathological changes in the lungs of $\vec{\circ}$ patients with scleroderma and MCTD include both parenchymal and vascular components. Besides $\overrightarrow{\widetilde{\omega}}$ mononuclear infiltration of the parenchyma, thickening of the alveolar capillary membrane andō vascular obliteration have been described. ${ }^{21-23}$

It is therefore not surprising that chest $x$-ray: 0 changes, which appear at a late stage of interstitialo lung disease, are related to a decreased capillary ${ }^{\omega}$ density in the entire group of patients (with and without CTD) but are not related to a decreased $\vec{C}$ capillary density in the group of patients with CTD. $\mathbb{D}$ Diffusion capacity, not included in this study, does $\frac{\mathbb{C}}{\mathbb{D}}$ not necessarily need to correlate with capillary 3 density, as diffusion capacity is already decreased in early disease when the inflammatory processes $\vec{B}$ dominate vascular changes. ${ }^{24}$

Finally, we studied immunological and inflamm tory factors in relation to nailfold capillary findings. In one of our former studies on patients with RP we found a positive correlation between immunological findings and systemic involvement in patients pre-ڤँ senting with RP. ${ }^{12}$ There is circumstantial evidence $\stackrel{\unrhd}{\varrho}$ that immunological abnormalities precede the de- $\overrightarrow{\vec{F}}$ velopment of organ failure. ${ }^{9}$ The primary event in 3 the pathogenesis of the vascular abnormalities in secondary RP, before obliteration of capillaries, is probably increased vascular permeability. This may result from endothelial damage mediated by im- 을 munological processes. Although circulating im- $\frac{5}{3}$ mune complexes are not considered as a major factor in the pathogenesis of scleroderma, increased $O$ levels have been described in MCTD and scleroderma. ${ }^{25} 26$ Autoantibodies may be patho-음 genic either by participation in immune complexes, $\rightarrow$ by antibody-dependent cytotoxicity, or by in-vitro․ㅡㄹ. penetration of living cells, as is especially observed N for nRNP antibodies. ${ }^{27}$ The decreased capillary density and increased number of enlarged loops in 0 patients with immunological abnormalities argues $\omega$ for immunologically mediated vascular disease. Immunological processes may result in local in- 6 flammation. In our study inflammatory parameters in the peripheral blood, such as ESR, CRP, and + fibrinogen, were also related to decreased capillary ${ }^{\circ}$ density. An increased level of fibrinogen also $\stackrel{\vec{D}}{\vec{D}}$ contributes to a state of hyperviscosity, another $\stackrel{\odot}{\Phi}$ 
factor of pathogenetic importance in RP. ${ }^{28}$

In summary, our observations point to capillary drop out and enlargement of capillary loops observed at microscopy as a reflection of local and systemic vascular disease in patients with RP. Thus capillary microscopy in patients with RP may indicate systemic involvement and possibly give a clue to its pathogenesis.

We wish to thank Marijke van der Giessen for performing the immune complex assays, and Maarten Andriessen for assisting in computerised data processing.

\section{References}

1 Bennett R, Holt P J L, Bywaters E G L. Survival in scleroderma. Ann Rheum Dis 1971; 30: 581-8.

2 Fessel W J. Systemic lupus erythematosus in the community. Arch Intern Med 1974; 134: 1027-35.

3 Ellman M H, Pachman L, Medof M E. Raynaud's phenomenon in initially seronegative connective tissue disease. $J$ Rheumatol 1981; 8: 632-5.

4 Kallenberg C G M, Wouda A A, The T H. Systemic autoimmune disease and Raynaud's phenomenon: a common, immunologically mediated, vascular basis? A hypothesis. Neth J Med 1984; 27: 322-6.

5 Rodnan G P, Meyrowitz R L, Justh G O. Morphological changes in digital arteries of patients with progressive systemic sclerosis (scleroderma) and Raynaud phenomenon. Medicine (Baltimore) 1980; 59: 393-408.

6 Campbell P M, LeRoy E C. Pathogenesis of systemic sclerosis: a vascular hypothesis. Semin Arthritis Rheum 1975; 4: 351-68.

7 Wiener Kronish J P, Solinger A M, Warnock M L, Churg A, Ordonez N, Golden J A. Severe pulmonary involvement in MCTD. Am Rev Respir Dis 1981; 124: 499-503.

8 Christian C L, Sergent J S. Vasculitis syndromes: clinical and experimental models. Am J Med 1976; 61: 385-92.

9 Follansbee W P, Curtiis E I, Medsger T A, et al. Physiological abnormalities of cardiac function in progressive systemic sclerosis with diffuse scleroderma. $N$ Engl J Med 1984; 310: 142-8.

10 Maricq $H$ R. Technique and rating scale for abnormalities in scleroderma and related disorders. Arthritis Rheum 1981; 24: $1159-65$.

11 Masi A T, Rodnan G P, Medsger Th A, et al. Preliminary criteria for the classification of systemic sclerosis (scleroderma). Arthritis Rheum 1980; 23: 581-90.

12 Kallenberg C G M, Wouda A A. The T H. Systemic involvement and immunological findings in patients presenting with Raynaud's phenomenon. Am J Med 1980; 69: 675-80.
13 Sharp G C, Irvin W S, Tan E W, Gould G C, Holman H R. Mixed connective tissue disease-an apparently distinct rheumatic disease syndrome associated with a specific antibody to an extractable nuclear antigen (ENA). Am J Med 1972; 52: 148-52.

14 Wouda A A. Photoelectric plethysmography of the fingers of persons with and without Raynaud's phenomenon during cold and warming up. Acta Med Scand 1977; 201: 519-23.

15 Kallenberg C G M, Vellenga E, Wouda A A, The T H. Platelet activation, fibrinolytic activity and circulating immune complexes in Raynaud's phenomenon. J Rheumatol 1982; 9: 878-84.

16 Van Wingerden I, The T H, Van der Giessen M, Rumke Ph. Demonstration of circulating immune complexes in melanoma by means of granulocyte phagocytosis tests. In: Peeters $\mathrm{H}$, ed. Protides of the biological fluids. Oxford: Pergamon, 1978: 346.

17 Houtman P M. Microvascular and immunological studies in Raynaud's phenomenon. Academic thesis. Groningen, the Netherlands.

18 Thompson R P, Harper F E, Maize J C, Ainsworth S K, LeRoy E C, Maricq H R. Nailfold biopsy in scleroderma and related disorders. Correlation of histologic, capillaroscopic and clinical data. Arthritis Rheum 1984; 27: 97-103.

19 Norton W L, Hurd E R, Lewis D C, et al. Evidence of microvascular injury in scleroderma and systemic lupus erythematosus: a quantitative study of the microvascular bed. $J$ Lab Clin Med 1968; 71: 919-33.

20 Nimelstein S H, Brody S, McShane D, Holman H R. Mixed connective tissue disease: a subsequent evaluation of the original 25 patients. Medicine (Baltimore) 1980; 59: 239-48.

21 D'Angelo W A. Fries J F, Masi A T, Shulman L E. Pathologic observations in systemic sclerosis (scleroderma). A study in fifty-eight autopsy cases and fifty-eight matched controls. Am J Med 1969; 46: 428-40.

22 Hunninghake G W, Fauci A S. Pulmonary involvement in the collagen vascular diseases. Am Rev Respir Dis 1979; 119: 471.

23 Furst D E, Davis J A, Clements P J, Chopra S K. Theophilopoulos A N. Chia D. Abnormalities of pulmonary vascular dynamics and inflammations in early progressive systemic sclerosis. Arthritis Rheum 1981; 24: 1403-8.

24 Spencer $\mathrm{H}$. Lung changes in progressive systemic sclerosis. In: Spencer J, ed. Pathology of the lung. Oxford: Pergamon, 1977: $741-6$.

25 Cunningham P H, Andreus B S, Davis J S. Immune complexes in progressive systemic sclerosis and mixed connective tissue disease. J Rheumatol 1980; 7: 301-8.

26 Seibold J R, Medsger T A, Winkelstein A, Kelly R H, Rodnan G P. Immune complexes in progressive systemic sclerosis (scleroderma). Arthritis Rheum 1982; 25: 1167-79.

27 Alarcon-Segovia D, Ruiz-Arguilles A, Fishbein E. Antibody to nuclear ribonucleoprotein penetrates live human mononuclear cells through Fc receptors. Nature 1978; 271: 67-9.

28 Blunt R J, George A J, Hurlow R A, et al. Hyperviscosity and thrombotic changes in idiopathic and secondary Raynaud's syndrome. Br J Haematol 1980; 43: 651-8. 